\title{
Neurophysiological Organization of the Superior Colliculus Pathways Related to Gaze Control
}

\author{
Minoru MAEDA and Shozo IsHII \\ Department of Neurosurgery and Casualty Center, \\ School of Medicine Juntendo University, Tokyo 113
}

\begin{abstract}
Summary
To elucidate the role of the superior colliculus in gaze control, intracellular responses in superior colliculus neurons (tectospinal, TS and tectoreticular, TR) to electrical stimulation of the vestibular nerve, the optic disk and contralateral superior colliculus were studied in chloralose-anesthetized cats.

1) Stimulation of the contralateral optic disk typically produced EPSPs in TS and TR neurons with disynaptic and polysynaptic latencies. Ipsilateral optic disk stimulation induced only polysynaptic EPSPs. Trisynaptic EPSPs were recorded following stimulation of the contralateral vestibular nerve. Polysynaptic EPSPs and EPSPIPSP sequences were evoked from the ipsilateral vestibular nerve. TS and TR neurons received excitatory inputs more consistently and strongly from the contralateral optic disk and vestibular nerve than from the ipsilateral ones.

2) Responses to sinusoidal oscillation indicate the presence of at least semicircular canal inputs to tectal neurons.

3) Vestibular afferent volleys converge on and facilitate interneurons which mediate trisynaptic retinotectal transmission. Visuovestibular interaction at the level of the interneurons may play an important role in visually triggered movement (gaze) accompanied by head movement.

4) Stimulation of the contralateral superior colliculus evoked monosynaptic IPSPs in both TS and TR neurons. It is very likely that these monosynaptic IPSPs partly participate in the production of tectotectal inhibition as was suggested from lesion experiments. Tectotectal projections which may mediate such inhibition were revealed by retrograde transport of HRP.
\end{abstract}

Key words: Gaze control, superior colliculus, visuovestibular interaction, eye-head coordination.

\section{Introduction}

It has been suggested that the superior colliculus is important in the mediation and integration of appropriate visually guided behavior in the cat (Sprague ${ }^{25)}$ ). In the superior colliculus, cells in the superficial layers discharge in response to visual stimulation and respond better when the visual stimulus is the target for a saccadic eye movement (Schiller and Stryker ${ }^{24)}$; Wurtz and Goldberg ${ }^{30)}$ ). Cells in the intermediate layer discharge before eye movement (Mohler and Wurtz ${ }^{20}$ ). In addition, electrical stimulation of the superior colliculus leads to movement not only of the eye
(Robinson $^{23)}$; Schiller and Stryker ${ }^{24)}$; Precht et al. ${ }^{22)}$; Grantyn and Grantyn ${ }^{8)}$ ) but also of the neck and body (Anderson et al. ${ }^{1}$; Crommelink et al. $\left.{ }^{4 \prime}\right)$. Ablation of the superior colliculus can produce profound deficits in visually guided behavior (Sprague and Meikle ${ }^{25)}$ ). On the other hand, the vestibular system has also been known to regulate eye and head movement (Lorente dé $\mathrm{NO}^{14)}$; Szentagothai ${ }^{28}$; Wilson and Maeda ${ }^{29}$; Maeda et $\mathrm{al}^{\left({ }^{15}\right)}$; Maeda and $\mathrm{Ishii}^{\left({ }^{6)}\right)}$ ). These results point to the importance of the superior colliculus in the coordination of eye and head movements during gaze and suggest the need for further studies, particularly on the interaction between the retinotectal and vestibular 
system presumably in mediating this behavior (Maeda et al. ${ }^{17), 18)}$ ).

\section{Materials and Methods}

Experiments were performed on 30 adult cats under $\alpha$-chloralose anesthesia. The animals were paralyzed with gallamine triethiodide and artificially ventilated. Bilateral pneumothorax was induced to improve instability. Blood pressure was monitored from one femoral artery and maintained between 90 and 130 $\mathrm{mmHg}$ by intravenous infusion of Karnigen (Japan Hoechst). The surface of the superior colliculus was exposed on both sides by removal of the occipital lobes, then intracellular recording from tectal neurons was performed with glass micropipettes filled with $3 \mathrm{M} \mathrm{KCl}$ or $2 \mathrm{M}$ potassium citrate. Bipolar electrodes (a fine $\mathrm{Ag}-\mathrm{AgCl}$ wire) were placed on the ipsi- and contralateral vestibular nerves. In some cases the cochlear nerve was cut on one side in the internal auditory meatus to rule out the pos- sibility that the observed responses in tectal neurons to labyrinthine stimulation were due to stimulus spread to the cochlear nerve. Bipolar electrodes were used for stimulation of the optic disk on both sides. A pair of sharpened tungsten needles was also used for bipolar stimulation of the contralateral superior colliculus. The projection areas of the impaled neurons were identified by their antidromic responses (Fig. 1A) to stimulation of the contralateral abducens nucleus and adjacent area, the contralateral prepositus hypoglossi or the $\mathrm{C}_{2}$ segment with bipolar tungsten electrodes. We classified cells projecting to the abducens, the prepositus hypoglossi or the vicinity of these nuclei as tectoreticular neurons (TR neurons), while cells projecting to the cervical region were classified as tectospinal neurons (TS neurons). The location of the neurons recorded intracellulary was reconstructed from the reference points (2-3 fast green dye marks made during and at the end of the experiments).

In three cats under sodium pentobarbital
L

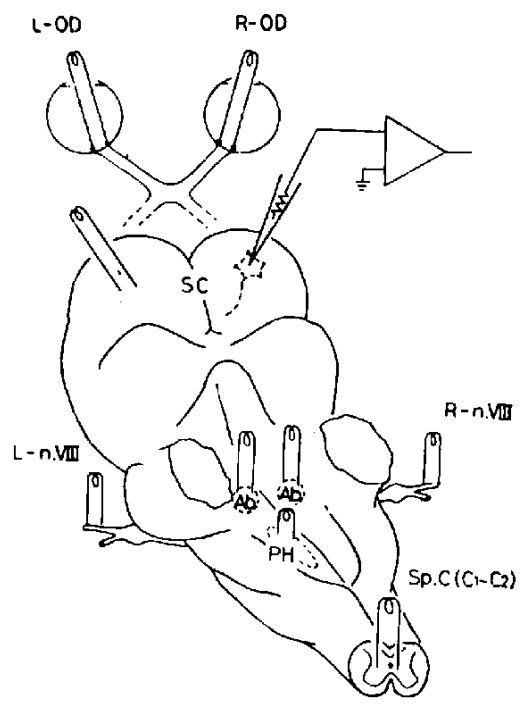

A
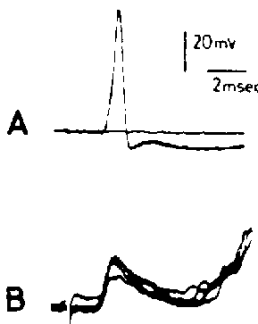

C

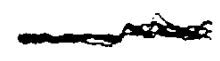

D
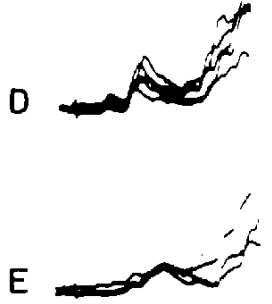

$\sum_{4 m s e c}^{2 m v}$

Fig. 1 Schematic drawing of experimental arrangement and responses of tectospinal neurons to optic disk and vestibular nerve stimulation. A: Typical example of the intracellularly recorded antidromic spike evoked by stimulation of the contralaleral cervical cord at the level of $\mathrm{C}_{2}$. B: EPSPs induced by single shocks to the contralateral optic disk, followed by late depolarization. C: Small EPSPs with long latency produced by ipsilateral optic disk stimulation. D: EPSPs following contralateral vestibular nerve stimulation. Note the early EPSPs are also followed by larger depolarization. E: Slowly rising EPSPs with longer latency after stimulation of the ipsilateral vestibular nerve. The voltage calibration in $E$ applies to B-D and the time scale in $\mathrm{E}$ also to B-D. Abbreviations: $\mathrm{Ab}$ : abducens nucleus, n.VIII: vestibular nerve, OD: optic disk, PH: praepositus hypoglossi, SC: superior colliculus, Sp.C: spinal cord. 
anesthesia, horseradish peroxidase (HRP, Sigma Type VI, $50 \%$ in $0.9 \%$ saline) was injected hydraulically into the unilateral superior colliculus. Retrograde cell-labeling was visualized after 2 days of survival. ${ }^{13)}$

\section{Results}

\section{Vestibular and visual inputs to tectal neurons}

\section{Tectospinal neurons}

Stimulation of the contralateral optic disk (ODc) evoked depolarization in TS neurons. Their amplitudes varied widely with stimulus strength and with the number of stimuli, and occasionally generated action potentials. The early part of the response could be followed by a later, larger depolarization (Fig. 1B). In a number of cases the early response was increased in amplitude by passing a hyperpolarizing current and decreased by depolarization, although little or no effect was observed in some cases. The most likely explanation of these results is that the depolarization is predominantly an excitatory postsynaptic potential (EPSP). In contrast to the contralaterally evoked response, stimulation of the ipsilateral optic disk (ODi) evoked very slowly rising depolarization (Fig. 1C) and in almost all cases no spike potentials were induced.

Single shocks to the contralateral vestibular nerve (Vc) induced EPSPs and occasionally generated action potentials. In many cases fast-rising, short latency EPSPs were followed by a later, long-lasting depolarization (Fig. 1D). Such short-latency potentials varied in amplitude with the strength of stimulation and responses to successive shocks in the train typically increased in size. In a few cases mixed effects, i.e., depolarization-hyperpolarization sequences, were also obtained. The most common potential changes induced from the ipsilateral vestibular nerve (Vi) were slowrising small EPSPs (Fig. 1E). Multiple stimuli were usually necessary to elicit PSPs and the responses to successive shocks were markedly faclitated.

The latencies of the EPSPs induced in TS neurons showed the following ranges: ODc: 2.2-2.7 msec (median: $3.0 \mathrm{msec}$ ); ODi: $4.0-$ $12.0 \mathrm{msec}(7.0 \mathrm{msec}) ; \mathrm{Vc}: 2.4-12.0 \mathrm{msec}(3.6$ $\mathrm{msec}$ ); and Vi: $4.0-13.0 \mathrm{msec}(9.7 \mathrm{msec})$. The histogram revealed a tendency for Vc- or ODc-latencies to be shorter than those evoked by $\mathrm{Vi}$ or ODi, and this was confirmed by comparing the latencies in the same cells (data not shown).

\section{Tectoreticular neurons}

Stimulation of the contralateral optic disk produced EPSPs with short latencies in almost all of the TR neurons. Later, slowly rising depolarization was obtained from the ipsilateral optic disk. Following contralateral vestibular nerve stimulation EPSPs were produced in TR neurons. In many cells the early EPSP was followed by a later, large depolarization. The most common potential change evoked from the ipsilateral vestibular nerve was very slowly rising depolarization although an IPSP or a mixture of EPSP and IPSP was observed in some cells (see also Table 1). Thus characteristics and patterns of synaptic potentials produced in TR neurons were very similar to those obtained in TS neurons.

The latencies of the EPSPs induced in TR neurons showed the following ranges: ODc: 2.1-9.0 msec (median: $2.8 \mathrm{msec}$ ); ODi: 3.2 $11.0 \mathrm{msec}(7.0 \mathrm{msec}) ; \mathrm{Vc}: 2.2-10.0 \mathrm{msec}(3.6$ $\mathrm{msec}$ ); and Vi: $2.4-12.0 \mathrm{msec}(5.4 \mathrm{msec})$.

In the case of neurons in the superficial

Table 1 Distribution of synaptic potentials evoked by stimulation of vestibular nerves and optic disks.

\begin{tabular}{|c|c|c|c|c|c|c|}
\hline & \multicolumn{3}{|c|}{$\begin{array}{c}\text { Tectospinal } \\
\text { neurons }\end{array}$} & \multicolumn{3}{|c|}{$\begin{array}{l}\text { Tectoreticular } \\
\text { neurons }\end{array}$} \\
\hline & EPSP & IPSP & lixed & EPSP & IPSP & Mixed \\
\hline \multirow{2}{*}{$\begin{array}{l}\text { Contra- } \\
\text { vestibular } \\
\text { nerve }\end{array}$} & 18 & 0 & 2 & 38 & 1 & 4 \\
\hline & $\overline{20}$ & $\overline{20}$ & $\overline{20}$ & $\overline{48}$ & $\overline{48}$ & $\overline{48}$ \\
\hline \multirow{2}{*}{$\begin{array}{l}\text { Ipsi- } \\
\text { vestibular } \\
\text { nerve }\end{array}$} & 7 & 0 & 1 & 18 & 5 & 3 \\
\hline & $\overline{10}$ & $\overline{10}$ & $\overline{10}$ & 40 & $\overline{40}$ & $\overline{40}$ \\
\hline \multirow{2}{*}{$\begin{array}{c}\text { Contra- } \\
\text { optic } \\
\text { disk }\end{array}$} & 18 & 0 & 0 & 40 & 0 & 0 \\
\hline & $\overline{18}$ & $\overline{18}$ & $\overline{18}$ & $\overline{46}$ & $\overline{46}$ & $\overline{46}$ \\
\hline \multirow{2}{*}{$\begin{array}{l}\text { Ipsi- } \\
\text { optic } \\
\text { disk } \\
\end{array}$} & 9 & 1 & 0 & 10 & 1 & 2 \\
\hline & $\overline{16}$ & $\overline{16}$ & $\overline{16}$ & $\overline{40}$ & $\overline{40}$ & $\overline{40}$ \\
\hline \multirow{2}{*}{$\begin{array}{l}\text { Contra- } \\
\text { superior } \\
\text { colliculus }\end{array}$} & 1 & 13 & 4 & 5 & 22 & 4 \\
\hline & $\overline{18}$ & $\overline{18}$ & $\overline{18}$ & $\overline{31}$ & $\overline{31}$ & $\overline{31}$ \\
\hline
\end{tabular}


layer which have been known to send their axons to deeper layers, ${ }^{12)}$ earliest latency of monosynaptic EPSPs occurred $1.4-1.9 \mathrm{msec}$ after stimulation of ODc and action potentials were usually generated shortly $(0.2-0.4 \mathrm{msec})$ after the onset of EPSP. Adding about 0.4 msec for synaptic delay in the superior colliculus to these values gives the expected shortest latency range of $2.0-2.7 \mathrm{msec}$ for a disynaptic pathway between the contralateral retina and neurons in the intermediate or deep layer. The early EPSPs recorded in TS or TR neurons indicate disynaptic transmission although approximately two thirds of the TS and half of the TR neurons recorded had a latency of more than $3.0 \mathrm{msec}$ suggesting that these EPSPs were evoked by a pathway containing three synapses. ODi-induced EPSPs had a latency of more than $4.0 \mathrm{msec}$ in TS neurons and $3.2 \mathrm{msec}$ in TR neurons, suggesting that these EPSPs were evoked via a pathway containing more synapses.

Figure 2 illustrates an experiment in which synaptic potentials were evoked in the same neurons by stimulations of the vestibular nerve and nucleus. Stimulation of the contralateral vestibular nucleus induced EPSPs in these tectal neurons with latencies ranging from 1.8 to $2.5 \mathrm{msec}$ and temporal summation was clearly observed, indicating the existence of disynaptic and polysynaptic connections between them. The latency differences between the vestibular nerve and nucleus-evoked EPSPs measured $0.5-2.8 \mathrm{msec}$. These results suggest the existence of the trisynaptic pathways linking the contralateral vestibular nerve and tectal neurons. In this case, the first synapse is located in the vestibular nuclei and the second synapse outside the vestibular nuclei (Fig. 2A).

The latency range $(4.0-8.8 \mathrm{msec})$ and the properties of IPSPs evoked in tectoreticular neurons by stimulations of the vestibular nerve suggest the presence of polysynaptic inhibitory connections between them.

Table 1 shows that stimulations of the vestibular nerve or optic disk caused excitation in a high percentage of tectal neurons and the occurrence of pure IPSPs was a rare event.

\section{Response to sinusoidal oscillation}

The cat was mounted on a stereotaxic apparatus located on a rotating device (Fig. 3A). We

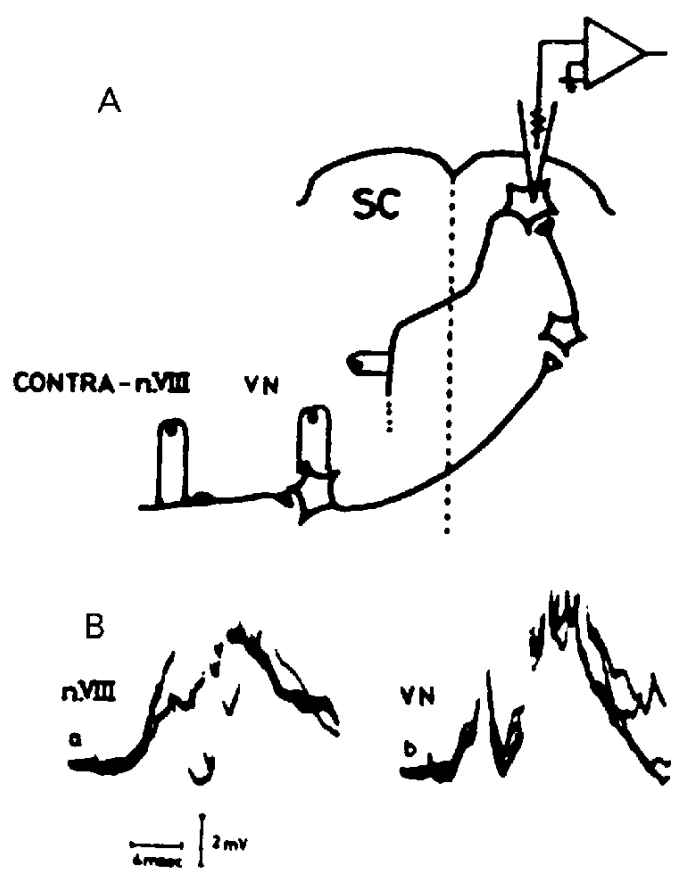

Fig. 2 Synaptic potentials evoked by stimulation of the vestibular nerve and nucleus. A: Schematic drawing of experimental arrangement and simplified pathway from the vestibular nerve to tectal neuron. B: EPSPs and spikes in TR neuron following contralateral vestibular nerve (n.VIII) or vestibular nucleus ( $\mathrm{VN}$ ) stimulation. Note EPSPs with shorter latency after vestibular nucleus stimulation.

recorded 11 tectal neurons extracellularly with fast green FCF. Out of the 11 tectal neurons, eight neurons were horizontal canal-related cells and three neurons were vertical canalrelated cells. Out of eight horizontal canalrelated cells, five cells increased their firing frequency with contralateral angular acceleration and decreased their frequency with ipsilateral acceleration. These neurons were called type II neurons. We have also recorded type I and type III tectal neurons. Fig. 3B shows responses of a horizontal type II tectal neuron to sinusoidal oscillation.

\section{Interaction of vestibular and visual inputs on tectal neurons}

The interaction between vestibular and optic disk volleys at internuncial levels was tested. Fig. 4 exemplifies the principal mode of interaction found in tectal neurons. Fig. 4A shows a control trisynaptic EPSP evoked in a 
A

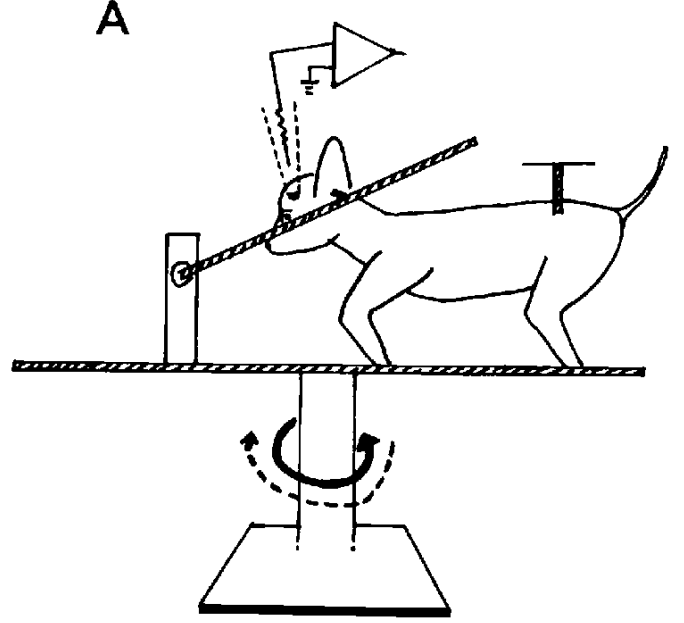

B
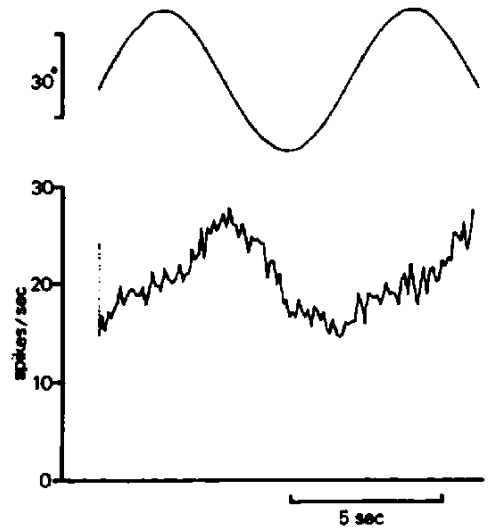

Fig. 3 Tectal neuron activity on the right side during turntable sinusoidal oscillation. A: Experimental arrangement using turntable. B: In upper trace, downward displacement of the curve indicates the leftward movement of the turntable. Unit spike was counted at each interval of $100 \mathrm{msec}$. The computer-averaged response represents the mean value of 30 successive sweeps.
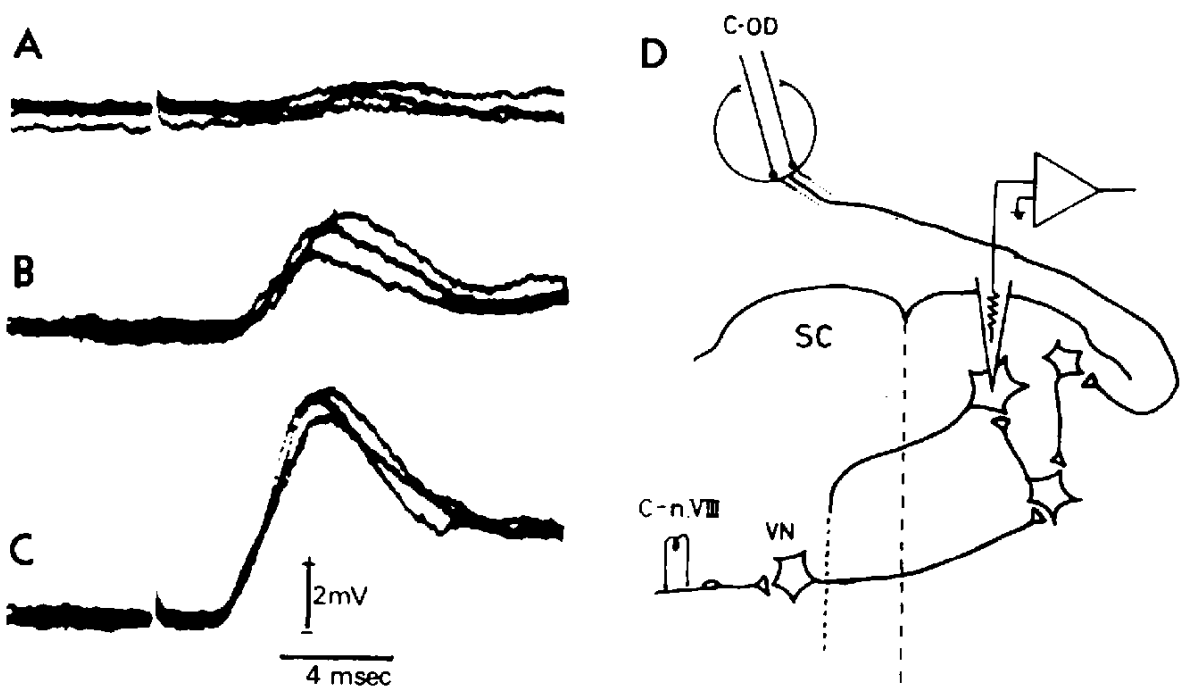

Fig. 4 Interaction between synaptic potentials evoked by stimulation of the vestibular nerve and optic disk. A: Small trisynaptic EPSPs evoked by stimulation of the contralateral optic disk. B: Response to contralateral vestibular nerve. $\quad$ C: The same test shocks as in A were preceded by the conditioning shocks to the vestibular nerve as in B. ODc volley produced a larger EPSP than the algebraic summation. D: Schematic drawing of simplified pathways from ODc and Vc to tectal neuron and the interaction between them. Voltage calibration and time scale in $\mathrm{C}$ apply to $\mathrm{A}$ and $\mathrm{B}$.

TR neuron by ODc-stimulation. When conditioned by $V c$ stimulation, the same ODc volley produced a larger EPSP than the algebraic summation of the two potentials (Fig. 4C). As schematically drawn in Fig. 4D, this finding indicates that the $\mathrm{Vc}$ volley converges on and facilitates interneurons that mediate trisynaptic excitation from the ODc.

\section{Effects of contralateral superior colliculus stimulation}

Stimulation of the contralateral superior col- 

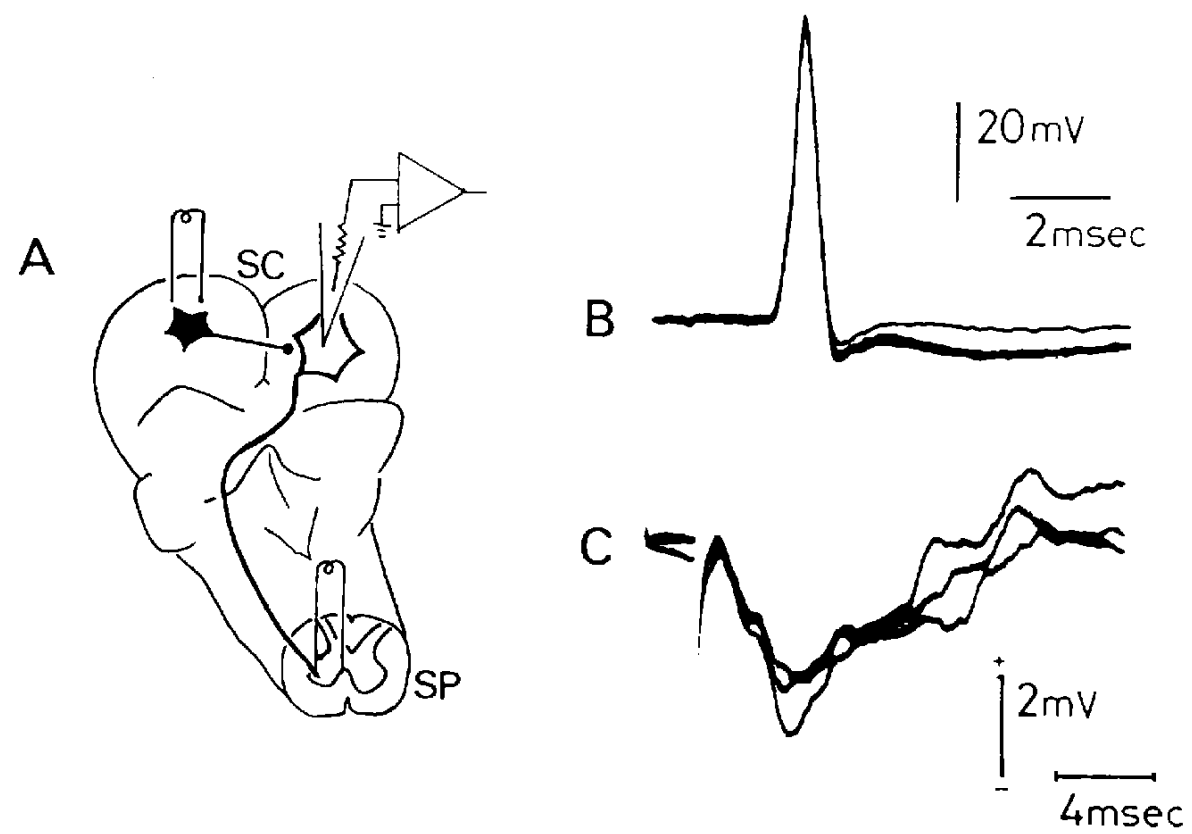

Fig. 5 Monosynaptic IPSPs evoked from the contralateral superior colliculus. A : Schematic drawing of simplified experimental arrangement and pathway of tectotectal inhibition. B: Antidromic spike evoked by a single shock delivered to cervical cord $\left(\mathrm{C}_{2}\right)$. C: IPSPs in tectospinal neuron after contralateral superior colliculus stimulation. ${ }^{18)}$

liculus (the intermediate or deep layer) evoked hyperpolarization (Fig. 5C) in TS and TR neurons, which was easily reversed by $\mathrm{Cl}^{-}$ ion injection and was therefore, an IPSP. In some cases IPSPs were preceded by small EPSPs, which rarely generated action potentials. The latencies of IPSPs ranged from 0.7 to $1.4 \mathrm{msec}$. The latencies of antidromic spikes of the commissural neurons projecting to the contralateral superior colliculus ranged from 0.4 to $1.2 \mathrm{msec}$. Adding about $0.4 \mathrm{msec}$ for synaptic delay to these values gives the expected shortest latency range of $0.8-1.6 \mathrm{msec}$ for a monosynaptic pathway. Therefore, the IPSPs evoked from the conıralateral superior colliculus should be monosynaptic (as shown in Fig. 5A).

\section{Tectotectal projections observed by retrograde cell labeling}

In pentobarbital anesthetized cats, horseradish peroxidase (HRP, Sigma type VI, $50 \%$ in $0.9 \%$ saline) was injected hydraulically into the unilateral superior colliculus. Figure 6 shows the injection site and HRP-labeled cells (visualized after 2 days of survival) in the superior colliculus and other structures.

Most the HRP-positive cells were located in the rostral portion of the superior colliculus and were distributed over the intermediate and deep layers. With regard to the distribution of the labeled cells in the brain stem, HRPpositive cells were found in the substantia nigra, the parabigeminal nucleus, the mesencephalie reticular formations, nucleus reticularis pontis, pars oralis of the descending trigeminus nerve root nucleus, nucleus reticularis parvocellularis and gigant cellularis.

\section{Discussion}

Our intracellular recording from $\mathrm{TS}$ and $\mathrm{TR}$ neurons shows that the vast majority of neurons were affected by stimulation of the vestibular nerve and optic disk. Although electrical stimulation of the whole vestibular nerve generated an unphysiological coactivation of many vestibular afferents, i.e. semicircular canal and macular system, the results of responses to sinusoidal oscillation indicate the presence of at least semicircular canal inputs (such as the horizontal semicircular canal) to 

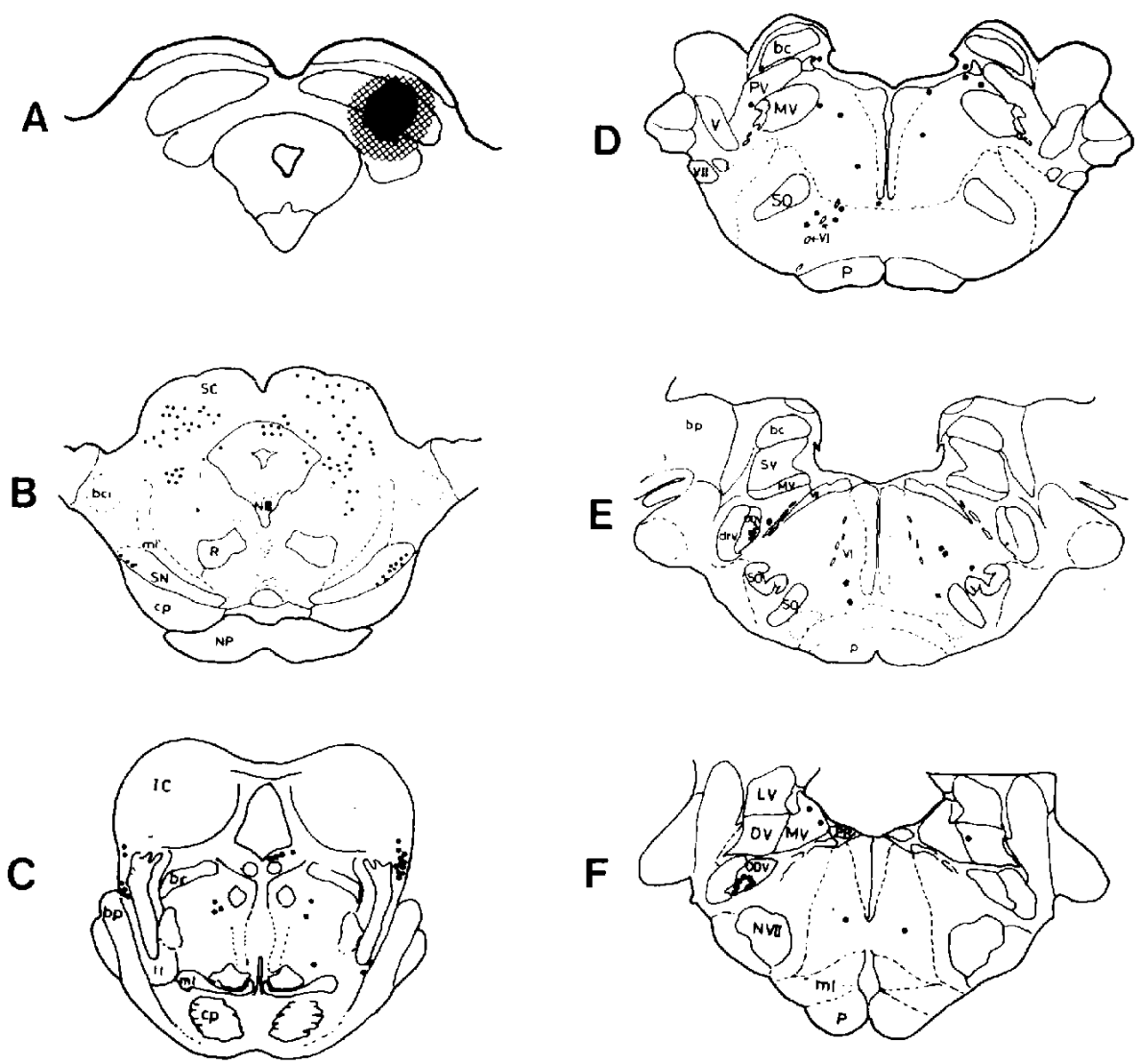

Fig. 6 Drawings of selected section (A-F) from an HRP experiment illustrating the distribution of HRP-labeled cells in the superior colliculus and other structures. A: The core (black area) of the HRP injection site in the right superior colliculus. The shaded area shows the medium brown halo surrounding the core. B-F: Drawing showing the distribution of HRP-positive cells in the mesencephalon and the pons after unilateral injection (as in A). Each drawing represents one section, and one dot on the cell-labeled neuron. Abbreviations: bc: brachium conjunctivum, bci: brachium colliculi inferioris, bp: brachium pontis, cp: cerebral peduncle, $\mathrm{drV}$ : descending root of the trigeminal nerve, $\mathrm{DV}$ : descending vestibular nucleus, IC: inferior colliculus, LV: lateral vestibular nucleus, ml: medial lemniscus, MV: medial vestibular nucleus, NP: nucleus pontis basales, ODV: nucleus tractus spinalis $\mathrm{n}$. trigemini (pars oralis), $\mathbf{P}$ : pyramid, $\mathrm{R}$ : red nucleus, SC: superior colliculus, SN: substantia nigra, SO: superior olive.

\section{tectal neurons.}

Horn and Hill ${ }^{11)}$ have found that a few visual cortical cells alter their preferred axis when the animal tilts. Bisti et al. ${ }^{2)}$ have shown that a large percentage of the cells of the superior colliculus alter their visual response as a function of the body tilt of the animal. Our results also indicate that vestibular and visual inputs converge on and facilitate the same interneurons. ${ }^{17)}$ Although the precise locations of these interneurons remain to be studied, the mesencephalic reticular formation and the nucleus reticularis pontis and parvocellularis where HRP-positive cells were found after injection of HRP in the superior colliculus (see also ref. 9), could be candidates for the locations of these interneurons. In any case, these interneurons may play an important role in the integrative control functions for visual and vestibular inputs, such as saccade accompanied by head movement.

Sprague ${ }^{26)}$ has proposed that the functional state of the superior colliculus may be influenced by both ipsilateral cortical facilitation 
and contralateral tectal inhibition. Reciprocal tectal inhibition has been reported on the basis of field analysis and extracellular unit recordings in the rat $^{7)}$ and in the cat. ${ }^{10)}$ We recorded monosynaptic IPSPs in TS, TR and also commissural neurons after stimulation of the contralateral superior colliculus. ${ }^{18)}$ It is very likely that these monosynaptic IPSPs at least partly participate in the production of tectotectal inhibition as was suggested from lesion experiments. HRP-positive cell bodies found in the colliculus contralateral to the injected side were distributed over the intermediate and deep layers (see also ref. 6 and 19). These results are consistent with the locations of fast green dye marks of commissural neurons electrophyscologically identified. Thus, these commissural neurons could be inhibitory interneurons producing monosynaptic IPSPs in the TS- and TR-neurons.

The superior colliculus neurons, which project to the vicinity of the abducens nucleus or to the upper cervical cord and presumably participate in control of eye and head movement, receive excitatory inputs predominantly from the contralateral optic disk and vestibular nerve. Visuovestibular interactions occurring at the levels of the interneurons and the deeper layer cell may play an important role in the production of visually guided eye movement toward contralateral hemifields accompanied by head movement. Bizzi and his collaborators ${ }^{3}$ ) demonstrated the sequence of eye-head movements and neuromuscular events that follow the sudden appearance of a target in the visual field of the monkey. Figure 7A illustrates the normal sequence of a saccade followed by a head movement in the same direction. To maintain fixation, the eyes perform a slow movement ( $\uparrow$ arrow) which is counter to that of the head and compensates for it. This compensatory movement is shown to be the result of a reflex activation induced by head turning (the so-called vestibulo-ocular reflex). ${ }^{5}$ Initial parts of eye ( $\uparrow$ arrows) and head movement are centrally programmed. Saccadic eye velocity in the head of the monkey is slowed down by an amount just equal to head velocity in space. ${ }^{3)}$ However, this is not the case in the cat (Pola and Robinson) ${ }^{21)}$ where quick-phase eye velocity in the head actually increases as head velocity increases. The neuronal organization analyzed here (as schematically shown in Fig. 7B) is consistent with this behavior in the cat. Thus, it may participate in the initial component of the visually triggered eye $(\uparrow \uparrow$
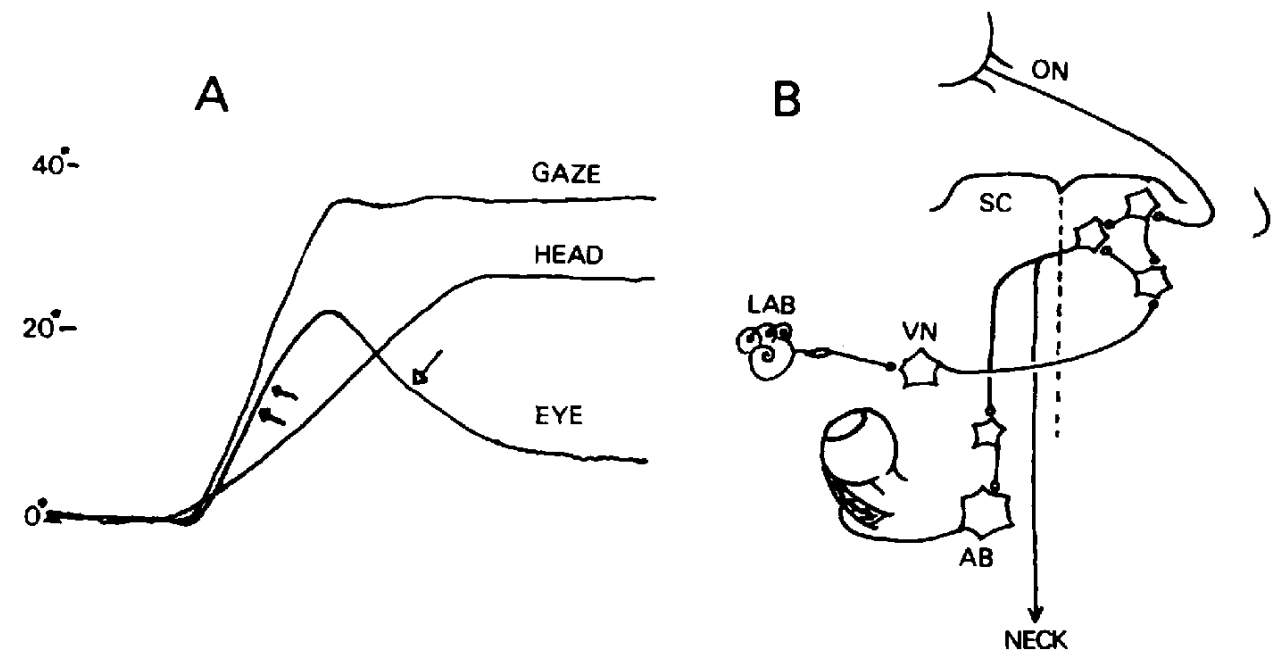

Fig. 7 Possible neuronal organization for visually triggered eye and head movement. A: Visually triggered eye-head coordination. Eye, horizontal eye movement consisting of initial component $(\| \uparrow)$ and compensatory movement $(\uparrow)$. Head, horizontal head movement. B: Summary of the neuronal organizations between the vestibular and the retino-tectal system. Abbreviations: AB: abducens motoneuron, LAB: labyrinth, Neck: neck motoneuron, ON: optic nerve, $\mathrm{SC}$ : superior colliculus, VN: vestibular nucleus. 
arrows) and head movements.

Tectal output neurons, which may participate in eye and head movement, receive monosynaptic IPSPs from the contralateral superior colliculus, and in addition, the commissural neurons also receive monosynaptic inhibition from the contralateral side. Since the two colliculi operate to orient the animal to opposite hemifields, this effect could serve to prevent competing responses in the opposite direction. ${ }^{6}$ ) In any case, our results show that the commissural neurons mediate suppressive effects on the contralateral tectal neurons and provide evidence for the intertectal suppression proposed by Sprague. ${ }^{26)}$

\section{References}

1) Anderson, M. E., Yoshida, M. and Wilson, V.: Influence of superior colliculus on cat neck motoneurons. I Neurophysiol 34: 898-907, 1971.

2) Bisti, S., Maffei, L. and Piccolino, M.: Visuovestibular interactions in the cat superior colliculus. $J$ Neurophysiol 37: 146-155, 1974.

3) Bizzi, E., Kalil, R. E. and Tagliasco, V.: Eyehead coordination in monkeys: Evidence for centrally patterned organization. Science 173: 452-454, 1971.

4) Crommelinck, M., Guitton, D. and Roucoux, A.: Retinotopic versus spatial coding of saccade: Clues obtained by stimulating deep layers of cat's superior colliculus. pp. $425-$ 435, In Baker R. and Berthoz, A. (eds): "Control of Gaze by Brain Stem Neurons," Elsevier. 1977.

5) Dichgans, J., Bizzi, E., Morasso, P. and Tagliasco, V.: Mechanisms underlying recovery of eye-head coordination following bilateral labyrinthectomy in monkey. Exp Brain Res 18: 548-562, 1973.

6) Edwards, S. B.: The commissural projection of the superior colliculus in the cat. $J$ Comp Neurol 173: 23-40, 1977.

7) Goodale, M. A. : Cortico-tectal and intertectal modulation of visual responses in the rat's superior colliculus. Exp Brain Res 17: 75-86, 1973.

8) Grantyn, A. A. and Grantyn, R.: Synaptic actions of tectofugal pathways on abducens motoneurons in the cat. Brain Res 105: 269286, 1976.

9) Grofva, I., Ottersen, O. P. and Rinvik, E.: Mesencephalic and diencephalic afferents to the superior colliculus and periaqueductal gray substance demonstrated by retrograde axonal transport of horseradish peroxidase in the cat. Brain Res 146: 205-220, 1978.

10) Hoffmann, K. P. and Straschill, M. : Influences of corticotectal and intertectal connections on visual responses in the cat's superior colliculus. Exp Brain Res 17: 75-86, 1973.

11) Horn, G. and Hill, R. M.: Modification of receptive fields in cells in the visual cortex occurring spontaneously and associated with body tilt. Nature 221 : 186-188, 1969.

12) Kanaseki, T. and Sprague, J. M.: Anatomical organization of pretectal nuclei and tectal laminae in the cat. $J$ Comp Neurol 158: 319 338, 1974.

13) Kristensson, K. and Olsson, Y.: Retrograde axonal transport of protein. Brain Res 29: 363-365, 1971.

14) Lorente dé No, R.: Vestibulo-ocular reflex arc. Arch Neurol Psychiat (Chic) 30:245-291, 1933.

15) Maeda, M., Magherini, P. C. and Precht, W.: Functional organization of vestibular and optic inputs to neck and forelimb motoneurons in the frog. $J$ Neurophysiol 40: 225243, 1977.

16) Maeda, M. and Ishii, S.: The neck, the labyrinth, the cerebellum and posture. Neurol Med Chir 18: 5-16, 1978.

17) Maeda, M., Shibazaki, T. and Yoshida, K.: Vestibular and visual influences on superior colliculus neurons in the cat. in "Integrative Control Function of the Brain. Ito. ed Vol. 1: 90-92, 1978.

18) Maeda, M., Shibazaki, T. and Yoshida, K.: Monosynaptic inhibition evoked in superior colliculus neurons following contralateral collicular stimulation. "Integrative Control Functions of the Brain." Vol. 2: 68-71, 1979.

19) Magalhaes-Castro, $B$.: Horseradish peroxidase labeling of cat tecto-tectal cells. Brain Res 148: 1-13, 1978.

20) Mohler, C. W. and Wurtz, R. H.: Organization of monkey superior colliculus: intermediate layer cells discharging before eye movements. J Neurophysiol 39: 722-744, 1976.

21) Pola, J. and Robinson, D. A.: Oculomotor signals in medial longitudinal fasciculus of the monkey. $J$ Neurophysiol 41: 245-259, 1978.

22) Precht, W., Schwindt, P. C. and Magherini, P. C.: Tectal influences on cat oculomotor neurons. Brain Res 82: 27-40, 1974.

23) Robinson, D. A.: Eye movement evoked by collicular stimulation in the alert monkey. Vision Res 12: 1795-1808, 1972.

24) Schiller, P. H. and Stryker, M.: Single-unit recording and stimulation in superior col- 
liculus of the alert rhesus monky. $J$ Neurophysiol 35: 915-924, 1972.

25) Sprague, J. M. and Meikle, Jr.: The role of the superior celliculus in visually guided behavior. Exp Neurol 11: 115-146, 1965.

26) Sprague, J. M.: Interaction of cortex and superior colliculus in mediation of visually guided behavior in the cat. Science 153: 15441547, 1966.

27) Straschill, $M$. and Rieger, P.: Eye movement evoked by focal stimulation of the cat's superior colliculus. Brain Res 59: 211-227,
1973.

28) Szenthgothai, J.: The elementary vestibuloocular reflex arc. $J$ Neurophysiol 13: 395-407, 1950.

29) Wilson, V. J. and Maeda, M.: Connections tween semicircular canals and neck moto. neurons in the cat. $J$ Neurophysiol 37: 346$357,1974$.

30) Wurtz, R. H. and Goldberg, M. E.: Activity of superior colliculus in behaving monkey. III. Cells discharging before eye movements $J$ Neurophysiol 35: 575-586, 1972. 